\title{
A TENDÊNCIA PRAGMATISTA E O SEU CARÁTER INSTRUMENTAL: inflexões teóricas presentes na área da Educação'
}

\author{
Giandréa Reuss Strenzel²
}

\section{Resumo}

Contemporaneamente, ocorre no interior da área da educação uma resignificação de conceitos, tendo como principais desdobramentos a noção esvaziada de conhecimento, a ênfase na experiência do indivíduo, no cotidiano e nas práticas empíricas. Esse corpo de ideias será discutido à luz da ontologia crítica, pois se acredita que seu estudo recoloca o problema filosófico essencial do ser social das coisas, abrindo a possibilidade de buscarmos outro tipo de entendimento do real, contra o predomínio manipulatório a que se vê a ciência na sociabilidade capitalista.

Palavras-chave: Ontologia crítica; educação; pragmatismo

\section{Abstract}

Contemporaneously, a reframing of concepts occurs in education, having as ramifications the emptied notion of knowledge, emphasis on the individual's experience, in daily life and in the empirical practices. These ideas will be discussed in the light of critical ontology because it is believed that their study replaces the essential philosophical problem of the social being of things, opening the possibility of seeking other types of understanding of what's real, against manipulative dominance which sees science in the capitalist sociability.

Key words: critical ontology, education, pragmatism

\footnotetext{
${ }^{1}$ DOI: https://doi.org/10.22409/tn.15i26.p9627

${ }^{2}$ Doutora em Educação. Professora do Centro de Ciências da Educação da UFSC, no Núcleo de Desenvolvimento Infantil. Pesquisadora do Grupo de Estudos e Pesquisa em Ontologia Crítica GEPOC/UFSC.(giandrea.reuss@ufsc.br)

TrabalhoNecessario - www.uff.br/trabalhonecessario; Ano 15, №26/2017
} 


\section{Introdução}

O universo ideológico contemporâneo carrega uma concepção de educação voltada para a capacidade de adaptação dos indivíduos aos processos de produção e reprodução do capital. Vemos uma forte descrença na capacidade de conhecer o mundo objetivamente, aonde sustenta-se o ceticismo nas teorias que defendem esse pressuposto, qual seja, o que pretende assegurar 0 conhecimento e o agir humano de um ponto de vista ontológico.

Do outro lado, o delineamento empiricista e tópico anuncia a tendência pragmatista e utilitária do conhecimento que toma dimensões cada vez mais avassaladoras nas várias esferas da vida social, subjugando a capacidade emancipatória que a teoria nos dá, no sentido de contribuir para a construção de uma contra-hegemonia. Essas questões são o mote do presente artigo, que procurará pô-las em debate por meio da crítica ontológica, bem como indicar de que modo esse corpo de ideias se manifesta no complexo educacional.

No Brasil, as políticas de ajustes para a educação gestadas no quadro histórico-social entre as décadas de 1980 e 1990, em nível nacional e internacional, implantaram novas medidas legislativas na Educação Básica e no Ensino Superior nas suas diferentes áreas científicas. A partir dessas reformas, a educação foi eleita como o mais importante condão de sustentação para a erradicação da pobreza e um dos principais determinantes da competitividade entre os países (Shiroma, Moraes, Evangelista, 2002).

Entre os protagonistas das políticas estão os organismos multilaterais, difusores de princípios que penetraram o meio educacional nacional e internacional por meio de documentos diagnósticos, analíticos e propositivos, realçando-se uma perspectiva de educação redentora, salvação para as adversidades sociais. A agenda é globalmente estruturada, porém se estrutura de modo diferente com relação aos países e continentes, devido não só à posição política e econômica de cada um, assim como à organização dos agentes econômicos. Contudo, o que torna a agenda semelhante é a prioridade ontológica do complexo econômico sob qualquer outro complexo. Isso significa afirmar que toda reestruturação ou resignificação ocorrida na área da educação tem como fundamento a manutenção do status quo da sociabilidade capitalista. 
Nas políticas para a primeira etapa da Educação Básica, a Educação Infantil, por exemplo, a Organização das Nações Unidas para a Educação, Ciência e Cultura (UNESCO), o Fundo das Nações Unidas para a Infância (UNICEF) e o Banco Mundial têm papel protagonista. Estes organismos estabelecem políticas compensatórias pautadas pelo discurso de atender pobremente a pobreza, com modelos a baixo custo e materiais sucateados (Rosemberg, 2002; 2010), (Campos, 2008). A educação é equacionada como mercadoria que deve ser repartida de forma justa, de modo que todos possam competir com as mesmas 'ferramentas'.

[...] em especial, nos países da Comunidade Europeia, as justificativas para essas políticas fundamentam-se em um discurso pelos direitos da criança quanto ao acesso à educação e aos bens culturais, e pela igualdade de direitos e oportunidades de homens e mulheres. Já nos países em desenvolvimento, o discurso para ricos e pobres é bastante diferenciado, particularmente quando estabelece políticas para expansão do atendimento. Quando o alvo é a população pobre, negra e de zona rural, essas políticas se pautam por um discurso da necessidade de atender pobremente a pobreza, que transparece de maneira clara nos documentos do Banco Mundial (Rosseti-Ferreira; Ramon; Silva, 2002, p. 66).

Por ocasião das reformas, o papel que o Estado exerce no desenvolvimento da educação se modifica. Além de promover políticas, o Estado passa a regular, orientar e criar condições para que a população dê prioridade à educação. As organizações não governamentais e a iniciativa privada entram em cena e assumem gradativamente o papel do Estado, que deixa de ser o provedor e passa a ser um organizador das relações capitalistas de produção. A avalanche de diretrizes, normatizações, resoluções etc., ocorrida na última década, teve o papel de regular a vida social. Nesse contexto, ocorre uma resignificação de conceitos e terminologias. Entre estas, as palavras que mais tomaram destaque foram: competência, consenso, verdade, conhecimento, entre outras. Elas adquiriram outros significados, adequados aos novos tempos.

Nesse âmbito, a perspectiva pragmatista, cujo foco é a racionalidade instrumental, a geração de conhecimentos úteis, é parte de um conjunto de procedimentos adotados nas reformas políticas nacionais e internacionais, as 
quais se inserem nos contextos das reformas da América Latina e da Europa. A educação entendida como alavanca para a sociedade do conhecimento produz uma política em que se exige aperfeiçoamento constante do sujeito, uma "educação ao longo da vida" para a integração na realidade em contínua mudança. A política globalizante, envidada pelas reformas dos anos 1990, deriva de uma sociedade cada vez mais adaptada aos ditames da sociabilidade capitalista.

\section{O conhecimento como utilidade para a orientação da prática}

Uma das questões fundamentais que se coloca diante dessa problemática, diz respeito às inflexões teóricas presentes no complexo educacional, mais precisamente, no campo da formação ${ }^{3}$ docente e as posturas relativistas das teorias que têm adotado a excessiva ênfase na experiência empírica e na redução da verdade ao que é útil. Esse é um movimento consensual na área da educação. Tal movimento

[...] prioriza a eficiência e a construção de um terreno consensual que reduz o horizonte da pesquisa e da formação docente ao saber tácito, à prática instrumental, plasmando-se o processo cognitivo no interior de limites que se definem pela empiria das tarefas cotidianas, pela formatação da capacidade adaptativa dos indivíduos, pela narrativa descritiva da experiência imediata e busca da eficácia da manipulação do tópico (Moraes, 2009, p. 317).

Essa é a noção esvaziada de conhecimento defendida pelo pragmatismo, em que o saber tácito e o conhecimento baseado na experiência empírica, retiram a reflexão crítica da formação docente, à medida que procura formar o professor capaz de pensar unicamente nas demandas que a prática lhe impõe. A prática diária torna-se o critério de reflexão sobre ela mesma e as ações dos indivíduos ficam reduzidas ao saber tácito. Sendo assim, atado à experiência imediata, o conhecimento se restringe ao individual, circunstancial e funcional. É analisado,

\footnotetext{
2 O conceito "educação ao longo da vida" é um eixo delineador difundido mundialmente pelas organizações internacionais, especialmente a UNESCO e a Comissão Européia (UE). Cf. Rodrigues (2007).

${ }^{3}$ Cf. Evangelista; Triches (2012; 2015), Triches (2010), Pimenta (2005), Brasil (2006).

TrabalhoNecessario - www.uff.br/trabalhonecessario; Ano 15, № 26/2017
} 
portanto, em sua eficácia de instrumento por meio do qual o indivíduo adapta-se ao meio ambiente.

Nesse universo ideológico, ocorre uma valorização de saberes e práticas construídas na ação cotidiana, no desenvolvimento de competências do futuro professor e no seu treinamento. Por outro lado, na formação inicial, o futuro profissional é formado para desenvolver competências, conceber teorias sobre sua própria prática e ser um investigador dela.

[...] o fascínio do modo de operar do ato educativo no quotidiano escolar no mais das vezes transforma a experiência imediata no limite da inteligibilidade. [...] a teoria é substituída pelo senso comum e, em consequência, não há inadequação entre o senso comum e a prática [...]. Ao se reduzir o senso comum ao praticismo, deduz-se "[...] a verdade ao que é útil para orientar a ação" (Küenzer; Moraes, 2006, p.185-186).

A centralidade na aquisição de competências, e não nos conhecimentos, deriva da noção de que o conhecimento prático é quem garantiria um bom trabalho pedagógico, sendo sustentado em "esquemas de pensamento prático" ou "esquemas de ação" escolhidos pelo professor em função da sua eficácia para responder imprevisibilidades e não em mediações teóricas (Scalcon, 2007).

O caráter instrumental contido na formação a leva a ser definida como um desenvolvimento de competências para a prática e seu entorno, criando mecanismos de reflexão por parte do adulto que, por sua vez, desenvolve competências na criança. O profissional deve construir conhecimentos na relação teoria e prática que "[...] permitam saber-ser, saber-estar e saber-fazer". Desenvolve, ademais, competências pessoais ligadas à criação de um ambiente facilitador de bem estar e competências profissionais mais ligadas à observação, análise e reflexão, gestão da instituição e intervenção pedagógica. É um utilizador e prático da investigação formativa. Nesse raciocínio, as competências "[...] são, então, estruturas mentais que orientam a ação. Ou seja, adequadas estruturas levam ao desempenho desejado" (Evangelista, 2004, p. 14).

A elaboração e a apropriação do conhecimento dão lugar à valorização do que é tópico, imediato e superficial, ou seja, a prática subsidia o desenvolvimento das competências. Trata-se, portanto, da noção de um sujeito que se molda, se 
adapta aos ditames do momento, isto é, "[...] a formação docente deve adequarse às demandas do 'mundo do trabalho' - abstraído da lógica do mercado" (Evangelista, 2004, p. 12).

Das críticas tecidas acima, não se trata de desqualificar a experiência do professor, adquirida no cotidiano de sua atividade profissional em sala de aula, mas destacar a insuficiência desta experiência para a captação do caráter estruturado do mundo, que determina os fenômenos empíricos e seguem para além deles, ou seja, os conhecimentos do campo empírico, circunscritos ao imediato, são insuficientes para dar conta da complexidade dos fenômenos educativos. Nesse sentido, Lukács (2012, p. 304) argumenta que:

Quer tomemos a própria totalidade imediatamente dada, quer seus complexos parciais, o conhecimento imediatamente direto de realidades imediatamente dadas desemboca sempre em meras representações (Lukács, 2012, p. 304).

Outra colocação interessante que se contrapõe à ação imediata do docente é de Martins (2004, p. 68). Sobre essa questão assevera que

[...] a captação da realidade por si só não assegura o seu real conhecimento, dado que este exige a construção da inteligibilidade sobre a realidade captada, isto é, uma vez conhecida ela precisa ser explicada. É na condição de possibilidade explicativa, ou abstração mediadora na análise do real, que a teoria, e, portanto, a transmissão dos conhecimentos clássicos entre as gerações, assume sua máxima relevância, possibilitando o estabelecimento de relações causais inteligíveis sobre os fenômenos, na base dos quais essa realidade passa a ser conhecida, compreendida e problematizada em sua essência.

Com o desenvolvimento de competências, o professor fica restrito ao campo de atuação da prática imediata. Nesse sentido, calcado nos limites do empírico, não é capaz de fazer as mediações sociais para ter domínio e uma compreensão aproximada da realidade, além de ficar distante de uma formação mais ampla, capaz de the fornecer subsídios que lhe permitam interferir e colaborar na transformação das condições da sua escola, da educação e da sociedade. A noção de competências é uma pedagogia integrante de uma ampla corrente educacional contemporânea denominada pedagogias do "aprender a aprender" (Saviani, 2007). Destaco, nesse ponto, a noção de competência 
trabalhada pelo autor, com o objetivo de indicar que tal abordagem carrega em si os mesmos pressupostos pragmatistas.

A pedagogia das competências alia-se às pedagogias do "aprender a aprender". Tal lema identifica-se com uma posição pedagógica progressista e inovadora e seu maior representante é o construtivismo. Surge nos anos de 1960, sob o lema da inovação e modernização, contrapondo-se à pedagogia tradicional. Sua repercussão decorre de suas interfaces com o universo ideológico contemporâneo.

Hoje em dia a pedagogia do «aprender a aprender» é a grande referência da orientação dominante. Tanto que está nos documentos oficiais e internacionais que depois se reproduzem em cada nação, como está nos meios de comunicação onde tentam convencer os professores das suas virtudes. O Relatório Jacques Delors das Nações Unidas sobre educação para o século XXI tem como eixo essa orientação do «aprender a aprender» e os países reproduzem isso nas suas políticas educativas. É uma pedagogia que tem origem na escola nova, no construtivismo de Piaget, que estava apoiado no keynesianismo. Agora foi recuperada, no contexto político do neoliberalismo, pelos pósmodernos. A ideia é que todo o ambiente é educativo - aprendese em diferentes lugares, em diferentes circunstâncias e ... também na escola! O argumento que dão para isso é que aquela visão rígida foi superada em benefício de uma sociedade flexível em que nada se pode prever. A escola não pode formar para 5 ou 10 anos, não se sabe como vai ser o futuro que está em constante mudança. Portanto, a escola não deve ensinar algo mas apenas aprender (Saviani, 2011, 5dias.net).

O lema "aprender a aprender" remete ao núcleo das ideias pedagógicas da Escola Nova, como foi referenciado acima. No escolanovismo esse lema se referia à valorização dos processos de convivência entre as crianças, do relacionamento entre elas e com os adultos, de sua adaptação à sociedade. Significava também adquirir a capacidade de buscar conhecimentos por si mesmo, se adaptar a uma sociedade entendida como um organismo em que cada indivíduo tinha um lugar e cumpria um papel social em benefício de todo o corpo social (Saviani, 2007). O "aprender a aprender" é também preconizado nos resultados de dois trabalhos de comissões internacionais da UNESCO. Um no início dos anos de 1970, conhecido como Relatório Faure (1972) e o segundo publicado nos finais de década de 1990, conhecido como Relatório Jacques

TrabalhoNecessario - www.uff.br/trabalhonecessario; Ano 15, № 26/2017 
Delors (1998). Esse último define linhas orientadoras para a educação mundial no século XXI.

Atualmente, o "aprender a aprender" liga-se à necessidade de constante atualização exigida pela necessidade da ampliação da esfera da empregabilidade. Essa visão veio a ser propagada de modo amplo no decorrer da década de 1990, a partir da publicação do Relatório Jacques Delors. No lema "aprender a aprender" configurou-se uma teoria pedagógica em que o mais importante não é ensinar e nem mesmo assimilar determinados conhecimentos. O que importa é aprender a aprender, isto é, aprender a estudar, a buscar novos conhecimentos, a lidar com novas situações.

Trata-se de preparar aos indivíduos formando as competências necessárias [...] Aos educadores caberia conhecer a realidade social não para fazer a crítica a essa realidade e construir uma educação com as lutas por uma transformação social radical, mas sim para saber melhor quais competências a realidade social está exigindo dos indivíduos (Duarte, 2001, p. 38).

O lema "aprender a aprender" atrela-se à desvalorização da transmissão do saber objetivo, contribuindo para a descaracterização do papel do professor, a negação do ato de ensinar e a isenção da escola de sua função social na transmissão do saber objetivo. Trata-se de um lema que sintetiza uma concepção de educação voltada para a capacidade de adaptação dos sujeitos aos processos de produção e reprodução do capital.

Se o conhecimento a ser ensinado aos futuros docentes tem um caráter instrumental, no pragmatismo opera-se também uma resignificação do papel do professor. O profissional é apenas um facilitador, um orientador, ou seja, desvincula-se da profissão sua função de ensinar, transmitir os conhecimentos históricos das gerações passadas. Esse pressuposto pode ser observado nas recomendações dos organismos multilaterais, como afirma Rodrigues, (2008, p. $15)$.

No documento produzido pela CEPAL e UNESCO (1995) reafirma-se que um dos fatores decisivos para o desenvolvimento dos países latino-americanos refere-se à elevação da qualidade dos recursos humanos. Em se tratando do professor, o discurso apela para a necessidade de reelaboração do que é ser professor, 
de uma nova identidade ajustada ao novo contexto tecnológico em que "o trabalho docente consistirá muito mais em orientar, dirigir, dar exemplos e animar, do que em transmitir os conteúdos da matéria." (CEPAL; UNESCO, 1995, p. 164). Deriva dessa mesma perspectiva a noção de que não basta apenas educar, é preciso assegurar o desenvolvimento de competências vinculadas à lógica do mercado e da chamada "sociedade do conhecimento". (Rodrigues, 2008, p. 15, grifos meus).

A organização do trabalho pedagógico e, por sua vez, o papel que o professor exerce nessa perspectiva, tem no seu cerne as ideias do polonês Suchodolski (1992). Entre outras questões, o autor parte da ideia da formação de um ser humano essencial; discorre sobre a educação enquanto afloramento das qualidades inatas do homem, a valorização excessiva da experiência do indivíduo como centro do processo.

Desse ponto de vista, a naturalização se faz presente, posto que a condição de historicidade do ser social é eliminada. Ao se naturalizar as relações sociais, o desenvolvimento humano não é considerado como resultado do desenvolvimento histórico "[...] porque os julga unilateralmente como processos e formações naturais, confundindo o natural e o cultural, o natural e o histórico, o biológico e o social no desenvolvimento psíquico da criança [...]" (Vygotski, 1995, p. 12). Sendo assim, sublinha Lukács (1979), provoca-se o cancelamento das contradições enraizadas na existência objetiva. Sob essa ótica, as relações sociais são vistas apenas na sua forma acabada e não em sua gênese real e contraditória. Como afirma Lukács (1979, p. 112), as "[...] relações categoriais ontológicas tão fundamentais como fenômeno-essência e singularidadeparticularidade-universalidade, são ignoradas, pelo que a imagem da realidade sofre uma excessiva homogeneização privada de tensões".

Dessa perspectiva, opera-se pelo pragmatismo uma naturalização das concepções de homem e sociedade na medida em que os fenômenos produzidos pelo homem ao invés de serem analisados como sociais e históricos são encarados como naturais. As determinações históricas das relações sociais são tomadas como determinações naturais e o indivíduo não é considerado como sujeito das relações sociais. Sendo assim, a formação do homem é tida como um processo natural, espontâneo e adaptativo e o seu desenvolvimento fica 
deslocado do processo histórico na medida em que o desconsidera como ser social.

É com esse sentido que o trabalho pedagógico postulado pelo pragmatismo é desenvolvido pelo professor, centrado no sujeito e não nas experiências sócio-históricas, resultantes do processo de desenvolvimento das relações humanas vivenciadas pelas necessidades postas historicamente pelo homem, como essenciais aos processos de produção e reprodução da sua existência. Sem história e sem conhecimento objetivo, resta aos indivíduos aprenderem a se adaptar da melhor maneira possível ao meio social no qual estão inseridos, sempre aprendendo a aprender, sem encontrar outro sentido que não o da estrita sobrevivência para aprendizagens vazias de conteúdo.

Ora, quem intervém propõe algo, em outras palavras, a intervenção supõe do professor a busca dos meios para realizar um fim. Não há como intervir sem fazer uma proposição, sem ensinar. Como afirma Lukács (2013, p. 48), "[...] todo processo teleológico implica numa finalidade e, portanto, numa consciência que estabelece um fim. [...] com o ato de pôr, a consciência dá início a um processo real, exatamente ao processo teleológico".

É por meio da atividade orientada e dirigida por outros homens que o homem se educa, adquire conhecimentos e habilidades, forma e desenvolve suas capacidades. Isto vem a favorecer o seu desenvolvimento e criar novas necessidades e possibilidades. Por isso, a conduta intencional das pessoas que convivem com o sujeito e agem sobre o seu desenvolvimento, é imprescindível para que a aprendizagem ocorra. $\mathrm{O}$ trabalho pedagógico realizado pelo professor recai, então, sobre a apropriação da experiência histórico-cultural e dos conhecimentos produzidos por nossos antepassados e não somente por um guiar, observar e animar, como preconizam os documentos internacionais citados acima que, por sua vez, tem na sua gênese o caráter pragmático dos conhecimentos. A aprendizagem é força motriz do desenvolvimento da inteligência e da personalidade do sujeito.

$\mathrm{Na}$ descoberta do conhecimento subjacente à prática, e utilizando-a como critério de reformulação dela própria, os professores ficam circunscritos à prática e acabam por apegar-se ao senso comum. Operando uma desvinculação da prática com a teoria, a prática é julgada como suficiente, contrapondo-se à teoria.

TrabalhoNecessario - www.uff.br/trabalhonecessario; Ano 15, № 26/2017 
Com a postulação de Küenzer (2003, p. 9), acrescento que:

A teoria passa a ser substituída pelo senso comum, que é o sentido da prática, e a ela não se opõe. Em decorrência, justificase uma formação que parte do pressuposto que não há inadequação entre o conhecimento do senso comum e a prática, o que confere uma certa tranquilidade ao profissional, posto que nada o ameaça; o contrário ocorre em relação à teoria, cuja intromissão parece ser perturbadora.

Lukács (2012) faz uma interessante consideração a esse respeito, em razão da valorização da exclusiva eficácia do conhecimento científico na prática imediata. $\mathrm{Na}$ análise do filósofo húngaro, esse problema reside no conceito de práxis operado pelas correntes contemporâneas da filosofia da ciência. Entre elas, o autor cita o pragmatismo, no qual tem maior eficácia o conhecimento obtido por meio da prática imediata, que, por sua vez, encobre a essência. Com suas palavras,

A especificidade da relação entre essência e fenômeno no ser social chega até o agir interessado; e quando este, como é habitual, está baseado em interesses de grupos sociais, é fácil que se abandone seu papel de controle e torne-se, ao contrário, o órgão com o qual se encobre a essência, com o qual se faz com que ela desapareça, [...] (Lukács, 2012, p. 295).

No entanto, não se pode deduzir que o conhecimento da prática seja sempre um conhecimento válido e não passível de questionamento. $O$ conhecimento, afirma o autor, deve estar atrelado às categorias do universal e do particular. Ao se suprimir o conhecimento na experiência sensível, ou seja, na prática imediata, o sujeito isola o universal ou o cria no pensamento. No entanto, o singular - a prática imediata - não existe sem as determinações do universal e do particular e, por isso, não pode ser apreendido automaticamente pelo sujeito. Para uma correta apreensão da realidade é necessário obter o universal mediante a análise dos objetos e das suas relações.

Essa é uma constatação filosófica, como afirma o autor húngaro, que tem a função de crítica ontológica de falsas representações, isto é, tem como desígnio avivar a consciência científica a fim de restaurar no pensamento a realidade autêntica, existente em si.

TrabalhoNecessario - www.uff.br/trabalhonecessario; Ano 15, № 26/2017 
O professor tem uma função primordial. É ele na escola quem irá criar as mediações entre o sujeito da ação e o objeto do conhecimento a ser apropriado. Para que seu trabalho ocorra é fundamental a realização de posições teleológicas, ou seja, de ações intencionais. A prévia ideação do seu trabalho de intervenção tem objetivos definidos que levam os sujeitos da aprendizagem à apropriação dos conhecimentos, em patamares cada vez mais ampliados "[...] do inferior ao superior, do velho ao novo e mais progressivo [...] se movendo com frequência em zig zag ou retornando para trás" (Rosental; Straks, 1958, p. 341). É necessário também que o profissional transforme uma causalidade natural, que pode ser trazida pela criança, em uma causalidade posta. E para que isso se dê, é necessário que haja a investigação dos meios para que ocorra a posição de finalidade. Com outras palavras, é necessário que o professor, por meio da prévia ideação, conheça o que vai ser ensinado, os meios necessários para realizar a ação e as condições para que possa realizá-la. Desse ponto de vista, defendo uma formação teórica sólida, tanto inicial como continuada, que ultrapasse a concepção pragmática de conhecimento.

\section{Palavras finais}

No atual contexto de ceticismo epistemológico e relativismo ontológico apresentado, retomo aqui a questão principal delineada na introdução do artigo, qual seja, a do caráter instrumental da teoria presente hoje na área da educação, ou seja, o ideário pragmatista. Este parte de uma concepção de mundo, de sociedade, de história e de conhecimento. Também pode ser caracterizado como um sistema de crenças (Duayer, 2006), uma ontologia acrítica que pode ser utilizada para a manipulação dos fatos.

Lukács (2012), em seu tempo, antecipou muito dos acontecimentos na filosofia da ciência, ao afirmar que se fazia necessário à ciência orientar-se para o conhecimento adequado da realidade existente em si e esforçar-se para descobrir as verdades ontologicamente fundadas. Do contrário, sua atividade seria reduzida à sustentação da práxis imediata. Em suas palavras: "Se a ciência não pode ou conscientemente não deseja ir além desse nível, então sua atividade transformase numa manipulação dos fatos que interessam aos homens na prática" (Lukács, 2012, p. 47). O autor alertou, desde o início da década de 1960, sobre a

TrabalhoNecessario - www.uff.br/trabalhonecessario; Ano 15, № 26/2017 
impossibilidade ontológica da humanidade negligenciar em definitivo as questões ontológicas. Ocorreu que as categorias ontológicas do campo filosófico e científico foram excluídas pelo positivismo desde o início do século XX. Segue-se daí que a verdade é reduzida ao que é útil. Tal posicionamento é recorrente na área educacional, como vimos, e vem provocando consequências desastrosas.

Quanto menos desenvolvida for a ciência, maior é a frequência de enquadramento de falsas teorias gerais do conhecimento, ou falsas crenças, que funcionam na imediaticidade. Conhecimentos adquiridos na prática, aqueles que têm utilidade, permanecem circunscritos à sua direta utilização na prática imediata e são considerados suficientes para a manipulação de determinados complexos, com o auxílio dos conhecimentos práticos. Pode-se atribuir a esse respeito, o problema ontológico da diferença, da oposição e da conexão entre fenômeno e essência, pois, "[...] na vida cotidiana, os fenômenos frequentemente ocultam a essência de seu próprio ser em lugar de iluminá-la" (Lukács, 2012, p. 294). Se circunscrever somente à prática imediata, sem sair dos seus limites seria um equívoco, pois "[...] pode-se pensar a educação como um continuum, jamais totalmente concluído, mediando sempre a abertura de novos campos às ações humanas nas escolhas dos sujeitos" (Moraes, 2009, p. 332).

A valorização instintiva da realidade imediatamente dada, das coisas singulares e das fáceis percepções é uma atitude apenas periférica perante a realidade, reflete Lukács (2012). Ao contrário, há que se partir da totalidade do ser na investigação das próprias conexões e buscar apreendê-las em todas suas múltiplas e intricadas relações, no grau máximo de aproximação possível. Para tanto, trata-se de recorrer à capacidade emancipatória que a teoria pode dar aos sujeitos. Nesse sentido, as disciplinas que dão sustentação sólida ao futuro professor têm prioridade ontológica à sua experiência empírica.

O pragmatismo, acerca do qual fizemos algumas colocações, se insere naquilo que Moraes (2004) afirma possuir vitalidade e permanência, especialmente no caso do complexo educacional, a agenda pós moderna ${ }^{4}$, na qual estão expressas várias correntes teóricas. Não é lugar para tecer considerações sobre cada uma delas, porém o que neste momento importa

\footnotetext{
${ }^{4}$ Cf. Duayer; Moraes (1997, 1998), Moraes (1996, 2003), Wood; Foster (1999).

TrabalhoNecessario - www.uff.br/trabalhonecessario; Ano 15, № 26/2017
} 
ressaltar é que para estas teorias ocorre uma incapacidade de distinção entre a realidade objetiva e a maneira como a descrevemos ou a representamos. $\mathrm{O}$ mundo é visto como construído socialmente de acordo com jogos de linguagem, isto é, a construção social é linguística ou discursiva. A possibilidade do conhecimento objetivo é aqui visto como uma adequação empírica, o que Bhaskar (1977) chama de realismo empírico: uma ontologia implícita calcada no empírico, na experiência sensível do sujeito.

Nesse sentido, cada pessoa apenas pode supor que compartilha com o outro, conhecimentos aproximados, sem ter uma referência objetiva que assegure a identidade dos significados supostamente compartilhados. Fica evidente que uma vez que os conhecimentos são propriedades dos sujeitos e, portanto, subjetivos, não é possível transmiti-los objetivamente de uma pessoa para outra. Com esta posição, portanto, não há conhecimento objetivo e universal. A realidade é construída na atribuição de significados dados por cada sujeito. Esse é um posicionamento relativista, onde a prática emancipatória não pode apreender as legalidades objetivas que governam o mundo social. A prática bem sucedida é negada no relativismo. A certeza da prática imediata é a contrapartida necessária a toda e qualquer forma de ceticismo em relação ao conhecimento objetivo da historicidade do ser social. A historicidade do mundo fica como absoluta contingência, acaso. Sendo assim, resta aos sujeitos circunscreverem sua prática ao imediatamente dado, anistórico, positivo (Duayer, 2010).

Ao contrário do que defendem os posicionamentos relativistas, sustento que a sociedade não é uma construção do pensamento dos sujeitos e, sim, expressa o conjunto das relações dentro das quais os sujeitos ou grupos se situam (Bhaskar, 1998). Qualquer atividade considerada científica procura se aproximar das causas e estruturas subjacentes dos fenômenos manifestos e, dessa maneira, fornecer uma explicação do que acontece com os fenômenos que experimentamos (Nanda, 1997).

As disputas teóricas são dependentes das concepções sobre o ser em que tais posições teóricas se fundamentam. Nesse sentido, toda teoria ou sistema teórico tem por pressuposto uma ontologia que compõe ou fornece um conjunto de fundamentos que delineiam o campo empírico no qual possuem validade. $\mathrm{O}$ que denota que disputas e debates entre teorias não supõe resolução empírica,

TrabalhoNecessario - www.uff.br/trabalhonecessario; Ano 15, № 26/2017 
pois o terreno empírico em relação ao qual são plausíveis é distinto, tem ontologias próprias. Portanto, a resolução só pode ser ontológica (Duayer, 2010).

Nesse ponto, concluo com Moraes (2009), que a opção está posta. Ou escolhemos uma teoria para perenizar o presente e administrar o existente, como é o caso das várias versões da epistemologia da prática que convergem no pragmatismo, ou uma teoria que execute uma análise crítica e imanente do existente. Que informe a prática científica consciente de si mesma, pois é no processo histórico crítico do conhecimento científico, que a teoria nos ensina como seres sociais, a capacidade emancipatória que nos torna conscientes do nosso papel de intelectuais e educadores que não ignoram que a transmissão dos conhecimentos e da verdade dos fatos. É um instrumento de luta, e tem a função de ser mediação na apreensão e generalização dos conhecimentos sobre a realidade objetiva, sob a perspectiva de domínio sobre a realidade segundo as exigências humanas.

\section{Referências}

BHASKAR, Roy. A Realist Theory of Science. London: Verso, 1977.

Societies. In: ARCHER et al. Critical Realism: Essencial Readings.

London: Routledge, 1998. p. 206-257.

BRASIL. Ministério da Educação. Conselho Nacional da Educação. Resolução $n$. 1, de 15/5/2006. Institui as diretrizes nacionais para os cursos de graduação em Pedagogia. Brasília, DF, 2006.

CAMPOS, Rosânia. Educação infanil e os organismos internacionais: uma análise dos projetos em curso na América Latina e suas repercussões no contexto internacional. Tese (Doutorado em Educação) - UFSC, Florianópolis, 2008.

DELORS, Jacques (org.). Educação: Um tesouro a descobrir. Relatório para a UNESCO da Comissão Internacional sobre Educação para o século XXI. 2a Edição - São Paulo: Cortez, 1998.

DUARTE, Newton. As pedagogias do 'aprender a aprender' e algumas ilusões da assim chamada sociedade do conhecimento. Revista Brasileira de Educação. Campinas, SP: Autores Associados; Rio de Janeiro, ANPEd, no 18, p.35-40, 2001.

DUAYER, Mario. Anti-realismo e absolutas crenças relativas. Margem Esquerda, São Paulo, v. 8, 2006, p.109-130. 
- Relativismo, certeza e conformismo: para uma crítica das filosofias da perenidade do capital. Revista da Sociedade Brasileira de Economia Política, v. 27,2010 , p. 58-83.

; MORAES, Maria Célia. Neopragmatismo: a história como contingência absoluta. Tempo, Niterói, vol. 2, no. 4, dezembro de 1997, p. 27-48.

; MORAES, Maria Célia. História, estórias: morte do real ou derrota do pensamento. Perspectiva, Florianópolis, v. 16, no. 29, jan-jun, 1998. EVANGELISTA, Olinda. A profissionalização docente na produção da ANPEd1995-2002. Relatório de pesquisa. Florianópolis, 2004.

; TRICHES, Jocemara. Professor(a): a profissão que pode mudar um país?. Revista HISTEDBR On-line, v. 15, p. 178-200, 2015.

KÜENZER, Acácia Zeneida. Competência como práxis: os dilemas da relação entre teoria e prática na educação dos trabalhadores. Boletim Técnico do SENAC. Rio de Janeiro, v. 29, n. 1, jan/abr., 2003.

; MORAES, Maria Célia M. Temas e tramas na pós-graduação em educação no Brasil. In: MOREIRA, Antonio F; PACHECO, José A. (org.) Globalização e educação: desafios para políticas e práticas. Porto: Porto Editora, 2006, p. 185-186.

Competência como práxis: os dilemas da relação entre teoria e prática na educação dos trabalhadores. Boletim Técnico do SENAC. Rio de Janeiro, v. 29, n.1, jan/abr., 2003.

FAURE, Edgar et al. Aprender a ser - La educación del futuro. Madrid: Ed. Cast. Alianza Editorial, S. A., 1972.

LUKÁCS, Georg. Ontologia do ser social - Os princípios ontológicos fundamentais de Marx. São Paulo: LECH, 1979.

. Para uma ontologia do ser social I. São Paulo: Boitempo, 2012.

Para uma ontologia do ser social II. São Paulo: Boitempo, 2013.

MARTINS, Lígia M. Da formação humana em Marx à crítica da pedagogia das competências. In: DUARTE, N. (Org.). Crítica ao fetichismo da individualidade. Campinas, SP: Autores associados, 2004. p. 53-73.

MORAES, Maria Célia M. Os "Pós-ismos" e outras e outras querelas ideológicas. Perspectiva, Florianópolis, v. 14, no. 25, jan-jun, 1996.

- Ceticismo epistemológico, ironia complacente: indagações acerca do neopragmatismo de Richard Rorty. In: MORAES, M.C.M. (org.) Iluminismo às avessas: produção de conhecimento e políticas de formação docente. Rio de Janeiro: DP\&A, 2003.

TrabalhoNecessario - www.uff.br/trabalhonecessario; Ano 15, № 26/2017 
. O renovado conservadorismo da agenda pós-moderna. Cadernos de $\overline{P e s q u i s a, ~ S a ̃ o ~ P a u l o: ~ F C C, ~ v .34, ~ n . ~ 122, ~ p . ~ 337-3357, ~ m a i o / a g o . ~} 2004$. . Indagações sobre o conhecimento no campo da educação. Revista Perspectiva, Florianópolis, v. 27 n. 2, 315-345, 2009.

NANDA, Meera. Restaurando o real: repensando as teorias da ciência sócioconstrutivistas. Social Register. Ed. Leo Panich, 1997. Tradução de Mario Duayer, UFF, 1999, f. 1-39.

PIMENTA, Selma G. (2005). Professor reflexivo: construindo uma crítica. In: PIMENTA, Selma G.; GUEDIN, Evandro (Org.). Professor reflexivo no Brasil: gênese e crítica de um conceito. $3^{a}$ ed. São Paulo: Cortez, 2005.

RODRIGUES, Marilda M. Educação ao longo da vida: eterna obsolência humana. 182f. Tese (Doutorado em Educação) - UFSC, Florianópolis, 2008.

A noção de educação ao longo da vida como eixo orientador das políticas de educação para jovens e adultos. Cadernos ANPAE, v. 8, 2009, p. 118.

ROSEMBERG, Fúlvia. Organizações multilaterais, estado e políticas de educação infantil. Cadernos de Pesquisa, São Paulo, n. 115, p.25-64, mar. 2002.

ROSENTAL, M. M. ; STRAKS, G. M. Categorias del materialismo dialético. México: Editorial Grijalbo, S. A., 1958.

ROSSETI-FERREIRA, Maria Clotilde; RAMON, Fabíola; SILVA, Ana Paula S. Políticas de atendimento à criança pequena nos países em desenvolvimento. Cadernos de Pesquisa, São Paulo, n. 115, p.65-100, mar. 2002.

. Educação infantil pós-LDB: avanços e tensões. In: SOUZA, Gizele de (Org.). Educar na infância: perspectivas histórico-sociais. São Paulo: Contexto, 2010.

SAVIANI, Dermeval. História das ideias pedagógicas no Brasil. Campinas, SP: Autores Associados, 2007.

Aprender a aprender: um slogan para a ignorância. In: 5 dias.net. http://5dias.net/2011/05/27/aprender-a-aprender-um-slogan-para-a-ignorancia/ Acesso em: 9 jul. 2015.

SCALCON, Susi. A influência pragmática na produção sobre a profissionalização do professor. Relatório de pesquisa de pós-doutorado. UFSC, 2007.

SUCHODOLSKI, Bogdan. A pedagogia e as grandes correntes filosóficas. Pedagogia da essência e a pedagogia da existência. Lisboa: Livros Horizonte, 1992.

TrabalhoNecessario - www.uff.br/trabalhonecessario; Ano 15, № 26/2017 
SHIROMA, Eneida. O; MORAES, Maria Célia M. de; EVANGELISTA, Olinda Política educacional: o que você precisa saber sobre... 2. ed. Rio de Janeiro: DP\&A, 2002.

STRENZEL, Giandréa Reuss. Formação humana, conhecimento e prática nos processos de formação docente para a educação infantil: apontamentos a partir da ontologia crítica de Lukács. Relatório de pesquisa. mimeo. UFSC, Florianópolis, 2012.

TRICHES, Jocemara. Organizações multilaterais e curso de pedagogia: a construção de um consenso em torno da formação de professores. $272 \mathrm{f}$. Dissertação (Mestrado em Educação) - UFSC, Florianópolis, 2010.

; EVANGELISTA, Olinda. Curso de Pedagogia, organizações multilaterais e o superprofessor. Educar em Revista (Impresso), v. 1, p. 185-198, 2012.

WOOD, Ellen M.; FOSTER, John B. Em defesa da história. Marxismo e pósmodernismo. Rio de Janeiro: Zahar, 1999.

VYGOTSKI, Lev. Obras Escogidas III. Madrid: Centro de Publicaciones del MEC y Visor Distribuiciones, 1995.

Recebido em: 09 de novembro de 2016 Aprovado em: 15 de maio de 2017 Pubicado em: 4 de junho de 2017 